International Journal of Business Management, Entrepreneurship and Innovation, Volume 3, Issue 2, 2021, PP 15-30, ISSN 2707-8027

\title{
Online Group Interaction and the Development of Virtual Identity Among the Youth in Nairobi County, Kenya
}

\author{
Deckillah S. Omukoba ${ }^{1}$, Tommy K. Kiilu ${ }^{2}$ \\ ${ }^{1,2}$ Department of Communication, Media, Film and Theatre Studies, Kenyatta University, Kenya
}

\begin{abstract}
The internet has taken the new role of community through online groups where youth congregate to interact, exchange ideas and pursue interests. As they engage in self-expression and self-presentation online, it is important to understand how virtual identity is negotiated and formed in those spaces. This research analyzed online group interaction and the development of virtual identity among the youth in Nairobi County. The objectives guiding the study were: 1) To establish the extent to which the youth are part of online groups. 2) To establish the reasons that influence the youth to join online groups. 3) To determine the extent to which online group membership develops the virtual identity of the youth. The independent variable in the study is online group interaction while the dependent variable is virtual identity development. Review of literature in this research is based on various aspects of online group interaction in relation to its potentiality in forming the virtual identity of group members. The communication theory of identity (CTI) and uses and gratification theory $(U \& G)$ were adopted to form the theoretical framework for this research. The study employed a mixed method research design in which the main methods used in data collection included; Self-administered questionnaires, Focus Group Discussions, and In-depth interviews. This study comprised four focus group discussions of ten members each sampled from two Universities in Nairobi County, a young professionals group in Kasarani sub-county and a youth support group in Mwiki Nairobi, County. Eight social media experts were interviewed. A cross-sectional survey targeting the youth was conducted in two Universities in Nairobi in which 384 questionnaires were administered to the targeted respondents. The data collected was analyzed qualitatively and quantitatively based on the themes derived from the objectives of this study. Quantitative data was analyzed using the SPSS software, while the qualitative data was analyzed using the NVIVO software. The three-dimensional identity model by Crocetti, Rubini, \& Meeus, (2008) was also used to analyze objective three of this study. Findings revealed that the independent variable of online interaction influenced the performance of users online leading to the development of a virtual identity that they are associated with. Equally the reasons for interaction online such as bonding and bridging influence the kind of self-expressions that the users exhibit online thus characterizing their virtual identity. The study concluded that because the youth are engaging online, they are performing ever-changing identities. There is therefore a need for them to be guided for positive outcomes. Equally the study made the following recommendations, firstly, online group interactions could be used positively as a platform for social interaction and change. Secondly, more online groups that address youth related matters should be created as a way of addressing this transitional stage in life. The study suggested further research in rural context and the adult segment.
\end{abstract}

Key Words: Innovations in Communication, Online Group Interaction, Virtual Identity DOI 10.35942/ jbmed.v3i2.187

Cite this Article:

Omukoba, D., \& Kiilu, T. (2021). Online Group Interaction and the Development of Virtual Identity Among the Youth in Nairobi County, Kenya. International Journal of Business Management, Entrepreneurship and Innovation, 3(2), 15-30. https://doi.org/10.35942/jbmed.v3i2.187 
International Journal of Business Management, Entrepreneurship and Innovation, Volume 3, Issue 2, 2021, PP 15-30, ISSN 2707-8027

BBMED

\subsection{Introduction}

Communication is commonly understood as a primary resource for enacting social identity and displaying membership in social groups (Miller, 2010). The basic symbolic interaction principle states that society shapes self which then shapes behavior (Sulimani-Aidan, Melkman, \& Hellman, 2019). As society shifts and the medium of communication majorly transitions from analogue to digital; it is important to study how interactions on these online communities affect the self. Scholarly interest in issues of self-identity has exploded across disciplines within the humanities and social sciences in recent years. Common to these concerns are the assumptions that self-identity is not an a priori, not given or fixed, but created in the process of communication (Savolainen et al, 2021). Several researchers including Kaakinen et al (2020), Chan (2019), Crocetti, Rubini, and Meeus (2008) have acknowledged the importance of studying identity formation as a developmental process in addition to investigating differences between existing and new identity statuses. This also assumes that social institutions and values are produced and reproduced by individuals in interaction. Particularly important was research conducted by Bachinni et al (2017) that developed an explicitly ecological understanding of the multiple identities self. This work showed how a change in environment (from face to face to online for example) can lead to two parallel developments of identity. This is evidenced by Dunne and Lawlors' (2010) study on adolescents' use of Social networking sites (SNS). Their study was carried out among girls aged 12 to 19 years and focused on one social networking site (SNS) 'Bebo'. Findings revealed an active use of Bebo for personal motives and gratifications in terms of presenting and managing a certain identity and persona in a social context. One respondent in their findings stated:

"Sometimes you look at people's profile pictures and go "oh my god", what are they at"? Some of the stuff they say about themselves is exaggerated as well; they are trying to make themselves look cool." The need to perform an identity on the online space is not a new phenomenon in communication. According to Goffman (1959), dramaturgy is a sociological perspective that is a component of symbolic interactionism and is used in sociological analysis of everyday life. According to this perspective, individuals perform actions in everyday life as if they were performers on a stage, and their identity is performed through roles (Lumen, 2019). Each performance is a presentation of the self and that everyone seeks to create specific impressions in the minds of others. This universal drive is called impression management. Individuals manage others' impressions of them by successfully portraying themselves "onstage," or in public. People present themselves to others based on cultural values, norms, and expectations. Most of the time, people seek to meet society's expectations (Brown, 2011).

With the inception of Social networking sites (SNS) it is observed that they may have provided stronger relationship than face-to-face method which is why more young people rely on their usage than have offline interaction (Dembinska et al 2020). Through social networking sites (SNS), the youth are more willing to disclose information about themselves and to foster deeper interaction without any restrictions like how face-to-face conversation would be. For example, in the online conversation, the youth can ask deep personal questions such as someone's sexual orientation without offending the others (Favotto et al, 2017). These kinds of conversations may be harder to share with parents, relatives or even friends offline. Therefore, the youth prefer online communication than real-world contact. In the 21 st Century, there is an increasing migration to the online space, $59 \%$ of the global population is online (Clement, 2020). A good percentage of the global population online is the youth (70\%) (ITU, 2017) most of whom are digital natives; who are a generation of people growing in an era of ever present technology, computer, internet and gadgets (Nikou et al, 2020). Several Researches shows that the youth 
International Journal of Business Management, Entrepreneurship and Innovation, Volume 3, Issue 2, 2021, PP 15-30, ISSN 2707-8027

BNED

account for the highest population online. A research conducted by Pew Research Center (2019) revealed that $71 \%$ of youth in America use more than one social networking site. According to Simelab (2018), 89.7\% of Kenyans are internet users, while $85.6 \%$ of youth have enrolled in more than one social networking site. It therefore follows that the youth are a vibrant group online and therefore the need to study their behavior online and how their interactions on these online groups develop their identity.

The youth largely create and recreate themselves in this new environment by managing impressions. Anderson and Jiang (2018) reported that many young people acknowledge the unique challenges - and benefits - of growing up in the digital age, while some say they at times feel overwhelmed by the drama on social media and pressure to construct only positive images of themselves online. In a study by Nguyen (2017) on the effect of social media on the youth development, majority of respondents acknowledged that excessive use of social media affects their relationship with parents and siblings at home. Majority of the respondents reported to have experienced being isolated from relatives and friends and a high percentage of the respondents reported to have become more introverted after a period of time. The social structure of the online environment has an impact on the selves that can be sustained in that setting, just the same way particular selves can be sustained in certain physical settings like school, church, or social clubs due to the nature and requirement of that environment. Whenever the youth come into contact with each other on the online space, identity questions always arise, since from a very young age they have learned how to 'read' the status and identity symbols of people (Nikou et al, 2020).

The concept of identity therefore carries the full weight of the need for a sense of who one is, together with the change in surrounding social contexts. Changes in the groups and networks in which people and their identities are rooted and in the societal structures, subject positioning, dominant societal ideologies and practices in which those networks are embedded are becoming more common and complex (Pegg et al, 2018). There seems to be a constant struggle and disconnect between who someone is, the identity their appearance performs, what they want to express and how they want to be identified. The challenge of reconciling the avowed and ascribed identity is by far a challenge that many youth have to deal with (Lawless, 2015). Identity is a complex phenomenon that takes different forms based on prevailing circumstances and the changing thereof, which is why it is very easy to be caught up in the crisis of identity as one shifts over to the online space because they equally have to perform actions in that space. These crises create internal conflict and emotional upheaval, thereby causing the youth to examine and question their values, beliefs, and goals. As they explore new possibilities, they may form new beliefs, adopt different values, and make different choices (Morelli, 2018). It is important to note that a crisis of identity is not necessarily a bad thing, but a period of active exploration, where one attempts to figure out who they are or want to be (Zupanick, 2015).

Membership in these online groups influences how they think of themselves, how they think of others and how others think of them. These online groups impose expectations due to the constant comparison that goes on there. This comparison is used to evaluate performance, determine abilities and skills. Self-concept and self-esteem are also heavily influenced by the process of social comparison (Cherry, 2020). These comparisons can be with people who they know and interact with, with those whom they read about or see on social media or with anyone else they view as important (Jhangiani \& Tarry, 2014). This need for social comparison is enhanced and achieved online by certain affordances of technology, for example the use of filters affords the user the ability to change their appearance and look a certain way; the availability of maps enables the user to tag themselves to a location of their choice, the user 
International Journal of Business Management, Entrepreneurship and Innovation, Volume 3, Issue 2, 2021, PP 15-30, ISSN 2707-8027

IBMED

can even adopt a pseudo name online. This social comparison occurs primarily on dimensions on which there are no correct answers or objective benchmarks and thus on which we can rely only on the beliefs of others for information (Jhangiani \& Tarry, 2014). This disconnect between the ascribed and avowed identity can create a crisis in the life of the individual.

According to Cherry (2019), the youth must resolve the crisis of identity. This crisis represents the struggle to find a balance between developing a unique, individual identity while still being accepted and "fitting in" (Morelli, 2018). The youth face a challenge of determining who they want to be, and how they want to be perceived by others. This challenge is hugely experienced in the social networking sites, as there is a lot of surveillance and social comparison that happens there. Erikson (1950) believes that when the youth successfully navigate this crisis they emerge with a clear understanding of their individual identity and can easily share this "self" with others; therefore, they are healthy and well-adjusted. As a result, they are confident individuals who can freely associate with other people without losing their own identity. However, when the youth fail to navigate this crisis successfully, they are uncertain about who they are. Lacking this understanding, they can become socially disconnected and cut-off from others; or conversely, they can develop an exaggerated sense of their own importance and may adopt extremist positions (Zupanick, 2014).

This identity crisis challenge is magnified with the advancement of computer technologies and the youth engagements online; we as a society have been challenged to re-evaluate how we think about ourselves, as well as the relationship between a society and its occupation of a space (Strohmeir et al, 2021). The online space is powerful enough to shape the attitude and behavior of its users thus developing their identity there. For example, The National Centre on Addiction and Substance Abuse at Columbia University surveyed more than 2000 youths from the age of 17 to 27 years old over the phone and internet in order to identify the possible factors that affect substance abuse. The findings suggested that the youth who frequent social networking sites reported three times more likelihood to drink alcohol (26\% and 9\%), were five times more likely to use tobacco (10\% and $2 \%)$, and twice as likely to use marijuana (13\% and 7\%) than youth who do not (French, 2011). Studies also suggested that an exposure to substance use imagery is correlated with onset of use (Dal Cin, Stoolmiller \& Sargent, 2012). In other words, the youth who used social networking sites often are more likely to use alcohol or marijuana, and the risk is higher for those who have seen pictures of alcohol or drugs use of other peers. This speaks to the interactions that happen on these online groups and the effect they create on the youth who belong in them.

Literat (2021) observed in a study on computer subcultures, the focus was not so much on what people were doing with computers but rather how their interactions with computers led them to think differently, to feel differently, to relate differently, this was referred to as a 'romantic reaction' to computers. Computers have been helpful in showing us just how multifaceted and not one dimensional our lives are (Huang et al, 2020). New communication technologies have freed interaction from the requirements of physical co-presence and created an online presence and structure that cannot be ignored. These technologies have expanded the array of generalized others contributing to the construction of the self (Hatzipanagos \& Warburton, 2013). Several research foci emerge from this development: the substance of "I," "me," and the generalized other in a milieu void of place - the establishment of online groups - which are typically "communities of the mind," and thus the negotiation of co-present and cyberspace identities (Gunduz, 2017). With the availability of diverse online groups created in cyberspace, an individual tends to portray a certain aspect of themselves in one online group that can be totally different from another or who they are in the physical environment (CAK, 2019). The use of digital media therefore has diverse and manifold consequences for young people's 
International Journal of Business Management, Entrepreneurship and Innovation, Volume 3, Issue 2, 2021, PP 15-30, ISSN 2707-8027

IBMED

communication, their ways of learning, personal relationships, construction of identity, and formation of youth cultures (Roth-Ebner, 2019). These online environments have introduced new forums for performing one's identity. The lessons learned from peoples' use of online spaces underscores how the youth construct their identities and points to ways they can more competently communicate about themselves in the mediated environment.

Given the emerging trend of online communities, it is important to investigate the kind of identity that is developed in these online spaces of interaction. Particularly important was research conducted by Bachinni et al (2017) that developed an explicitly ecological understanding of the multiple identities self. This study showed how a change in environment - from face to face to online communication - can lead to two parallel developments of identity in an individual. According to Simelab (2018) 89.7\% of Kenyans are internet users, while $85.6 \%$ of the youth have enrolled in more than one social networking site. Anderson and Jiang (2018) reported that many young people acknowledge the unique challenges - and benefits of growing up in the digital age.

Kaigwa (2013) established that many online enthusiasts at times feel overwhelmed by the drama on social media and pressure to construct only positive images of themselves. From the foregoing studies, it emerges that community youth are either loosing identity or acquiring literally new identities online. Studies conducted in Kenya by Sikolia (2015), Waithaka, Ngulube and Onyancha (2015), Waithaka, (2013) and Ani's (2010), have established that high school as well as university undergraduate students, who mainly fall in the category of the youth intensively use the internet as they are constantly involved in online communication and have particular interest in social media such as Facebook, Twitter, YouTube, websites, Instagram, Emails, Whatsapp, Imo, blogs, telegram and other social platforms. These studies however have not made a connection between the youths' interactions in online groups and its implication on the development of a their virtual identity. With few studies carried out in this new virtual phenomena, the current study was inspired to investigate more on the subject matter. This study therefore investigated whether interactions the youth have with members of their online groups, leads to the development of a unique self-online identification, referred to as virtual identity.

\subsection{Statement of the Problem}

Online communities (or groups) have become common place across the globe. In the background to this study, it has been established that belonging to communities and interacting with members of given communities not only creates a sense of belonging but also creates members' identities, or senses of who they are. The nature of each community and the interaction that happens there constructs unique members' senses of themselves. As a new phenomenon, online communities are yet to be fully researched for their ability to foster community members' identities, or the character(s) of such identities for the members of online communities. Given the fact that the nature of online communities' members interaction is virtual, questions abound on the nature of identities formed during interactions by members of online communities (groups) as they also come from disparate socio-cultural physical communities. Previous research done on online communities has barely scratched the ground of online communities in Africa, yet it has been established that proliferation of online group membership in Africa, particularly in Kenya, is growing. It is therefore important for researchers in the field of communication to understand the reach of this online interaction by members of existing online social groups, the characteristics of the groups Internet users join, and the reasons they join such groups. This study therefore sought to establish the level of proliferation of online group membership by the youth in Nairobi County, Kenya, the reasons that motivate them to join such groups and whether online group membership develops in the 
International Journal of Business Management, Entrepreneurship and Innovation, Volume 3, Issue 2, 2021, PP 15-30, ISSN 2707-8027

IBMED

youth a virtual identity that is separate from their non-mediated identity. Knowledge gained from researching the foregoing will enable stakeholders in fields of human communication and sociology to understand the impact of consistent online social interaction for Internet users and its bearing on their selves-knowledge.

\subsection{Research Objectives}

The study's objectives were, to:

i. Establish the extent to which the youth in Nairobi County, Kenya are part of online groups.

ii. Assess the reasons that influence the youth to join online groups.

iii. Determine the extent to which online group membership develops the virtual identity of the youth in Nairobi County, Kenya, and its implication on the non-mediated identities.

\subsection{Literature Review}

\subsection{Theoretical Framework}

The Communication Theory of Identity (CTI) was developed by communication scholar Michael Hecht in 1993. The theory was developed based on theory and empirical data suggesting that communication is an element rather than just a product of identity. The communication theory of identity expands the notion of identity to view it as layered (Faulkner $\&$ Hecht, 2007). From this theorizing emerged CTI's definition of identity as the multilayered ways that individuals and communities socially construct themselves. Seeking to view identity as more processual and multi-layered, Communication Theory of Identity presents a more comprehensive or synthetic view of identity integrating community, communication, social relationships, and self-concepts, while locating identity in all these layers.

The basic overarching propositions that define identity are: Identities have individual, social, and communal properties. Identities are both enduring and changing. Identities are affective, cognitive, behavioral, and spiritual. Identities have both content and relationship levels of interpretation. Identities involve both subjective and ascribed meaning. Identities are codes that are expressed in conversations and define membership in communities. Identities have semantic properties that are expressed in core symbols, meanings, and labels. Identities prescribe modes of appropriate and effective communication. Identities are a source of expectations and motivations. Identities are emergent; they are obtained when we enter into relations with others who have identities. This layered perspective views one's identity formation and management as an ongoing process of communication with the self and with others rather than as a simple product of communication or basis for producing communication (Hope et al, 2019).

The theory posits that individuals internalize social interactions, relationships, and a sense of self into identities through communication. As the youth communicate online they develop a sense of their self-online and this self is what they manage and express and it becomes their virtual identity. In turn, identity is expressed or enacted through communication. In other words, the relationship between communication and identity is reciprocal; the way one communicates online forms their identity there, and the identity formed there determines how one communicates. From this perspective, communication helps build, sustain, and modify one's identity. The theory was found fit for the study, since it articulates this reciprocal relationship which enables the development of a unique identity online. This theory was applied in data collection particularly in the designing of focus group discussion questions geared to finding out how the youth communicate online as opposed to how they communicated offline. Each participant's viewpoint was analyzed as a trend or generalization 
International Journal of Business Management, Entrepreneurship and Innovation, Volume 3, Issue 2, 2021, PP 15-30, ISSN 2707-8027

IBMED

of their identity online. The responses given were analyzed according to what meaning and pattern they contribute to the virtual identity of the youth.

The Theory has been successfully used by other scholars in their study, an example being Matig (2018) in his dissertation on the effects of messaging on the health behavior decisions of recipients, with an understanding that being healthy is an 'identity'. The theory has also been used by Reimenschneider, Buche and Armstrong (2019) to examine the perceived challenges men face in the information systems workplace.

Although CTI proponents mainly considered the effects of various communication contexts beside online ones, this study offers the CTI as an identity-based approach to studying how online communication by members of virtual groups may lead to the identity formation of individual members. The theory provides a framework for understanding how the inter-relation of layers of identity playoff each other. These layers include the personal layer, the enactment layer, the relationship layer and the communal layer (Golden, 2015), all of which may merge in the process of online communication between members belonging to the same online groups. Hence, this study applied CTI within the context of online interactions to assess how identities are developed during online interactions. From the findings of the study, the researcher discovered that the main shortcoming of CTI theory lies in its inability to address the significance of the motivation communicators have in the choice of platforms through which they interact. This study therefore incorporated a second theory that was deemed sufficient enough in facilitating the capturing of data related to the reasons why the youth join online groups for interaction with others.

The study therefore, adopted the uses and gratification theory (Katz, Blumler \& Gurevitch, 1974). U\&G research has its foundation in communication research, originally focusing on motivations for choice of mass media and mass communication (Ling \& Pedersen 2003). The proponents of $U \& G$ argue that the technique is suitable for studying new communication technologies. As Perks and Turner (2019) put it, since new technologies present people with an increasing number of media choices, motivation and satisfaction become even more crucial components of audience analysis. Reiss et al, (2021) maintain that to focus fully on the social and cultural impacts of new communication technologies may be premature until we have grasped exactly how and why people are making use of these media channels.

This approach focuses on the consumer - the audience member rather than the message. The theory visuaizes the audience member to be a discriminating user of media. The audience is assumed to be active and goal directed. The audiences are largely responsible for choosing media to meet their own needs. The media are considered to be only one factor contributing to how needs get met, and the audience members are assumed to have considerable agency or in essence know their need and how to gratify those needs. The U\&G approach was propounded by Katz et al., (1974). The underlying assumption is that audiences are active and they seek out that content which provides the most gratification (Fawkes \& Gregory, 2001). Fawkes and Gregory (2001), further added that "the level of gratification depends on the level of need or interest of the individual". Katz et al., (1974) added that the U\&G approach is concerned with: "(a) the social and psychological origins of, (b) needs, which generate, (c) expectations of, (d) the mass media or other sources, which lead to, (e) different patterns of media exposure (or engagement in other activities), resulting in, (f) need gratifications and, (g) other consequences, perhaps mostly unintended ones". This model informed the present study in the sense that, (a) the youth have social and psychological needs, which (b) determine the Gratifications Sought (GS) through specific online groups and (c) have expectations of the different online groups 
International Journal of Business Management, Entrepreneurship and Innovation, Volume 3, Issue 2, 2021, PP 15-30, ISSN 2707-8027

\section{BE}

available, which (d) influences them to access these online groups, (e) and engage in different online activities, resulting in (f) gratifications obtained (GO) and, (g) other consequences (both positive and negative), mostly unintended, gained through the interactions with members of the online groups they joined. The Theory has been successfully used by other scholars in their studies on online communication, an example being, Sikolia (2015) in his thesis on factors influencing the choice of social networking sites among high school teenagers in Nairobi County. Roux (2020) applies this theory in examining uses and gratifications of mobile internet among South African Students.

The main criticism of the $U \& G$ theory is that measurement of the audience of any media usage is almost impossible and that the word gratification suggests greed to a large extent as opposed to satisfaction. As observed by among others, Egede and Chuks-Nwosu (2013) the selected results of audiences are difficult to correlate since not all people can attest to same satisfaction or gratification on any given subject in the media. Another criticism of U\&G is that the assumption of rationality by users is not real and that what is apparently satisfactory to person A might be the extreme opposite of what person B appeals even if they are in the same group environment (Ahad \& Anshari, 2017). However, U\&G theory is still a useful tool for evaluating reasons behind online users' choices of communication or integration platforms, for example online groups. Hence, this study applied U\&G theory to mine data related to Objective 3 of the study.

\subsection{Conceptual Framework}

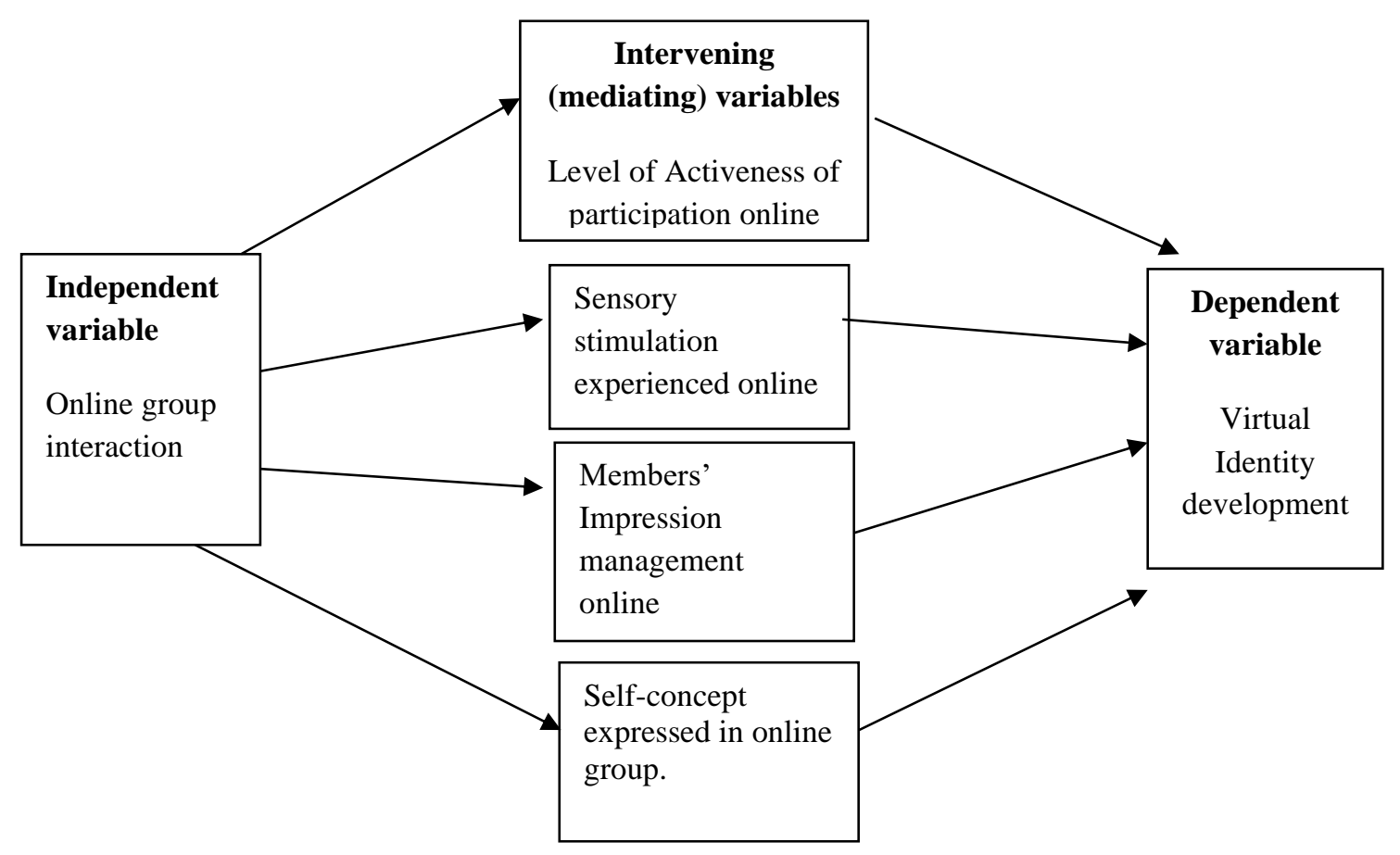

Figure 1: Conceptual Framework on Virtual Identity- 'Created by Researcher'

\subsection{Research Methodology}

This study adopted a mixed method qualitative and quantitative research design. The rationale for mixing is that neither qualitative nor quantitative methods are sufficient by themselves to address the elements of the research (Yin, 1989). The target population for this study was youth in Nairobi County aged between 18-26 years and who were members of an online group. 
International Journal of Business Management, Entrepreneurship and Innovation, Volume 3, Issue 2, 2021, PP 15-30, ISSN 2707-8027

BRMED

The age bracket was determined by the National youth policy of Kenya, that defines a youth as persons resident in Kenya in the age bracket of 15 to 30 years (Ministry of Youth Affairs, 2017). The study worked with 384 respondents from three sub-counties. Data from the selected sub-counties answered to the general demographic profiles of the respondents as well as objective one. The study also used snowballing and purposive sampling. The participants for the interview were purposively picked while the participants for the FGD were picked through snowballing sampling procedure.

In this study, the quantitative sample size was determined according to Cochran (1977) formulae designed for large populations. In Cochran's formula, any population of more than ten thousand $(10,000)$ people is considered infinite, and the sample size is calculated using the formula:

\section{n $=$ Z2. P. q/d2}

Where, $\mathrm{n}=$ sample size,

$\mathrm{Z}=$ the value at the chosen confidence interval (1.96 for a confidence interval of $95 \%$ ),

$\mathrm{P}=$ estimated population with attributes of interest which if infinite $\mathrm{p}=0.5$,

$q=1-p$, and $d=$ degree of desired precision ( 0.05 will be used in this study).

Therefore, the sample size $\mathrm{n}$ for this study was:

\section{$(1.962) \times 0.5 \times(1-0.5) /(0.05) 2=384.16$.}

The following procedures were used to collect data in this study: self-administered questionnaires, focus groups discussions and interviews. This research generated both quantitative and qualitative data, and therefore integration of these different types of data was done. The researcher first reported the quantitative statistical results followed by qualitative texts or themes. Before processing the responses for quantitative data, filled out questionnaires were serialized and checked for completeness and consistency and then coded to enable responses to be grouped into various categories for easy analysis. Statistical Package for Social Scientists (SPSS) was used to generate tables. The researcher did not intend to infer from this statistics beyond this profile which targeted objective one. Written and recorded discussions from interviews and FGDs were also analyzed using the NVIVO software.

\subsection{Data Analysis Results}

The study examined the demographic characteristics of the youth; the gender composition of the youth online group members was almost evenly matched with females being (52.6\%) and males $(47.4 \%)$. The age composition was also examined where a majority of the respondents (50.5\%) belonged to the 18-20 age brackets, while (39.3\%) belong to the 21-23 age bracket and the remaining (10.2\%) belong to the 20-26 age brackets. Regarding the respondents' level of education, the majority of them $(54.7 \%)$ were undergraduates, $(39.8 \%)$ were college students, $(4.4 \%)$ had a secondary diploma, while $(0.5 \%)$ represented both primary and postgraduate respondents. Findings on internet expenditure per month showed that $(29.4 \%)$ of the respondents spend 0-500 shillings per month on internet, (39.5\%) spend Ksh 501-1000 shillings per month on internet, (24.5\%) of them spend Ksh 1001-1500 shillings per month on internet, and (8.6\%) spend Ksh 1501-2000 shillings per month on internet use, while the remaining (6\%) spend above Ksh 2000 shillings per month on internet use.

The first objective of this study investigated the extent to which the youth are part of online groups. The findings recorded that $(54.4 \%)$ of the respondents belong to one to three online groups, while $(27.3 \%)$ belong to four to seven online groups. These findings corroborate 
International Journal of Business Management, Entrepreneurship and Innovation, Volume 3, Issue 2, 2021, PP 15-30, ISSN 2707-8027

IBMED

qualitative findings where participants affirmed membership to online groups as a connection factor. They credit these online groups for helping to build stronger friendships and exposing them to a more diverse world, but they express concern that these groups lead to drama and social pressure. According to Appel. et.al (2019) the future of social network interaction is group chatting, as opposed to one on one chats. Finnegan (2018) reported that applications that afforded users group interactions such as WhatsApp delivered a range of benefits, including breaking down the traditional hierarchies that can stunt effective communication within a team. These online applications provide methods of communication that are efficient as they enable members who are fragmented by physical boundaries to come together and interact.

The second objective of this study was to assess the reasons that influence the youth to join online groups. The participants affirmed that the need to connect with people they already know offline is paramount; the participants were interested in keeping in touch with previous friends from high school, or staying connected with family members with whom they are geographically apart. According to Claridge (2017), bonding social capital is a connection within a group or community characterized by high levels of similarity in demographic characteristics, attitudes and available information and resources. This connection happens between people who typically have strong close relationships, like family, friends or neighbors. These are people who know each other and interact frequently, and thus use social networking platforms to maintain their connection. The participants also affirmed that they join these online groups so that they can connect with likeminded people; people who share their interests whether it's professional, recreational, social or religious. They join these groups so that they can learn more from them, experience a feeling of belonging, receive support and identify with a community of others who share the same experiences. According to Putnam (2001), bridging social capital functions to bring together disparate members of the community. Bridging social capital provides low socio-economic status individuals with the potential to access resources outside of their constrained environment. Bridging enables people in virtual communities to share information and receive support from others with whom they share interests or similarities.

The third objective was to determine the extent to which online group membership develops the virtual identity of the youth. In the findings the participants affirmed that they present themselves in a particular way online because they consciously want to be perceived a certain way on the virtual space. They are aware that they are being watched and therefore it is very important to them that they feel appreciated, celebrated and affirmed online. They therefore manipulate their identity online to receive more likes and appealing comments; once they construct the virtual identity through the process of commitment, in-depth exploration and reconsideration of commitment. They commit to an online identity that gives them gratification and they spend their time online maintaining and improving on it for more and more gratification. If this need for gratification is not met, especially in the process of reconsideration of commitment, then they become dormant online or exit an online group.

This Virtual identity is a consequence of identity crises - which here refer to identity exploration - that arise as a result of a need to develop a self-online. The Virtual space, through affordances such as anonymity, synonymy and use of filters gives the youth ample opportunities for self-expression as opposed to real life spaces. The online groups provide some form of camaraderie to their members through bridging and bonding, though this trust is fragile and at times temporal because of the flame wars that go on these online groups. When their expectations are shuttered it results into one being dormant, inactive or leaving the online group. 
International Journal of Business Management, Entrepreneurship and Innovation, Volume 3, Issue 2, 2021, PP 15-30, ISSN 2707-8027

IBMED

These findings therefore reveal that the youth are at a critical stage in life where identity plays a major role in their operations, and therefore they need to 'frame' ideal identities in order to be 'accepted' by their peers. These findings corroborate previous studies by Boyd (2008) and Dunne and Lawlor (2010) who attributed the use of social networking sites (SNSs) among the youth to create personal identity. Roux (2020) also agreed that the youth were motivated by the need for image, fashion and status in their social networking sites (SNSs) use. This could have both positive and negative impacts considering aspects such as sexting, cyber bullying, terrorism and even human trafficking. Positively, these identities could cultivate good relationships, which can improve their performance in school and enhance mental health, awareness of the dangers of illicit drugs and sexually transmitted diseases.

\subsection{Conclusions and Recommendation}

\subsection{Conclusions}

The study made the following conclusions based on result findings. Firstly, the high percentage of youth belonging to multiple online groups is a clear indication of the importance that this category of people attaches to this medium. The appeal of online groups to the youth should be encouraged and probably harnessed for positive outcomes both socially and in academics; bearing in mind that the youth deal with tremendous pressure in the area of academics as well as the social challenges that surround their lives such as drugs, sex, unemployment, financial challenges, mental health, esteem issues and much more.

Secondly, the quest to enhance their virtual Identity motivated the youth to frame their presentations online. This can be attributed to the stage in their lives where they are transitioning into new responsibilities in life, implying that they are trying to find answers and affirmation in life. The fact that most youth would present an 'ideal' identity online shows that there is an identity crisis in this stage of life. Their perceived shortcomings influence them to create or manipulate their own presentation online. Equally, these youths seek acceptance among their online community members and thus switch their identities depending on which group they would feel comfortable belonging to. Among the features presented on these online groups is that: groups that stick to the agenda of the group and appreciate members equally without prioritizing others and trivializing or bullying others tend to thrive and have members participating more actively and feeling safe in these groups.

Lastly, the youth sought online group membership for user gratification, where they were inherently connected to the world outside the media system and bonded with persons whom they have established relationships with. They also engaged in bridging to connect with disparate members of the community, as well as to access resources outside of their constrained environment. Conversely, further investigation should be conducted among the youth to determine the consequences of this continual interaction online and whether it results into better connections offline.

\subsection{Recommendations}

There is a high population of youth who are online. The average youth in Nairobi County has access to a smartphone as well as internet connectivity. These youth are also members of up to five online groups on various social media platforms. This study therefore recommends a continued effort to enable connectivity across the country to be able to bridge the digital divide as well as facilitate the use of internet connectivity as an enabler to growth and development of the youth across the country. Institutions of learning - especially higher institutions of learning - should also prioritize internet connectivity for all students in their strategic plans. 
International Journal of Business Management, Entrepreneurship and Innovation, Volume 3, Issue 2, 2021, PP 15-30, ISSN 2707-8027

IBMED

The youth join online groups for bonding social capital as well as bridging social capital. The online community enables them to connect with those they know offline as well as those whom they share common goals, ambitions or challenges. This study therefore recommends the creation of awareness to the power of these online groups. These can be done through further studies that investigate the impact of online group membership to one's offline life to the extent of dealing with issues such as addictions, transitions of life in the areas of career, marriage, business etc and how the interactions and advisement received online empowers the members to deal with the vicissitudes of life. The study also recommends the use of online groups as an avenue for learning. Educators need to appreciate these online groups as a platform where learning can take place. Teachers should not shy off from joining these online groups and even teaching from these platforms, neither should they trivialize learning that happens there.

The youth form a virtual identity as a result of interacting on these online groups. The interactions that happen there plays a big role in the shaping of a unique identity online that one identifies with and is known for. This study therefore recommends a consideration on the value of one's interaction online in the enhancement of their offline lives. The identities developed online can go a long way in working for or against an online user whether one becomes a socialite or a successful entrepreneur can be achieved online. The youth should therefore be guided on the kind of identity they develop online.

\section{References}

Ahad, A. D., \& Anshari, M. (2017). Smartphone habits among youth: Uses and gratification theory. International Journal of Cyber Behavior, Psychology and Learning (IJCBPL), $7(1), 65-75$.

Anderson, M. (2018). A Majority of Teens Have Experienced Some Form of Cyberbullying. Retrieved on 3.11.2019 from: https://www.pewresearch.org/internet/2018/09/27/amajority-of-teens-have-experienced-some-form-of-cyberbullying/

Anderson, M. \& Jiang, J. (2018). Teens' Social Media Habits and Experiences. Retrieved on 12.3.2020 from: https://www.pewresearch.org/internet/2018/11/28/teens-socialmedia-habits-and-experiences

Ani, O. E. (2010). Internet access and use: A study of Undergraduate Students in Three Nigerian Universities. The Electronic Library, 28(4), 555-567.

Appel, G., Grewal. L., Hadi, R. \& Stephen, A.T. (2019). The Future of Social Media in Marketing. J. of the Acad. Mark. Sci. 48, 79-95 (2020). https://doi.org/10.1007/s11747-019-00695-1

Atas, A. \& Celik, B. (2019). Smartphone Use of University Students: Patterns, Purposes, and Situations. Retrieved on 2.04.2020 https://files.eric.ed.gov/fulltext/EJ1214011.pdf .

Boyd. D. (2008). Why Youth Heart Social Network Sites: The Role of Networked Publics in Teenage Social Life. Youth Identity and Digital Media. Edited by David

Brown, A. (2011). Relationships, Community, and Identity in The New Virtual Society. Futurist, 45 (2), 29-34.

Cherry, K. (2020). Social Comparison theory in psychology. Retrieved 8.07.2020 from: https://www.verywellmind.com/what-is-the-social-comparison-process-2795872

Cherry, K. (2019). Identity vs role confusion in psychosocial stage . Retrieved 8.07.2020 from: https://www.verywellmind.com/identity-versus-confusion-2795735

Cochran, W. G. (1977). Sampling Techniques (3rd ed.). New York: Wiley.

Crocetti, E., Rubini, M., \& Meeus, W. (2008). Capturing the dynamics of identity formation in various ethnic groups: Development and validation of a three-dimensional model. Journal of Adolescence, 31, 207-222. doi: 10.1010/j.adolescence.2007.09.002 
International Journal of Business Management, Entrepreneurship and Innovation, Volume 3, Issue 2, 2021, PP 15-30, ISSN 2707-8027

BMED

Dal Cin, S., Stoolmiller, M., \& Sargent, J. (2012). When Movies Matter: Exposure to Smoking in Movies and Changes in Smoking Behavior. Journal of Health Communication, 17, 76-89

Egede, E. A., \& Chuks-Nwosu, E. (2013). Uses and gratification theory and the optimization of the media in the privatization of state owned enterprises in Nigeria. Journal of Economics and Sustainable Development, 4(16), 202-212.

Faulkner, S. L., \& Hecht, M. L. (2007). Tides in The Ocean: A Layered Approach To Culture and Communication. In B. B. Whaley \& W. Samter (Eds.), Explaining Communication: Contemporary Theories And Exemplars (pp. 393-402). Mahwah, NJ: Lawrence Erlbaum

Favotto, L., Michaelson, V., \& Davison, C. (2017). Perceptions of the influence of computermediated communication on the health and well-being of early adolescents. International journal of qualitative studies on health and well-being, 12(1), 1335575.

Fawkes, J., \& Gregory, A. (2001). Applying communication theories to the Internet. Journal of Communication Management, 5(2), 109-124.

Fields, D. A., Kafai, Y. B., \& Giang, M. T. (2017). Youth computational participation in the wild: Understanding experience and equity in participating and programming in the online scratch community. ACM Transactions on Computing Education (TOCE), 17(3), 1-22.

French, E. (2011). Social Media Use Tied To Substance Abuse Risk In Teens. Family Practice News , 41

$\mathrm{Fu}$, J. (2018). Chinese youth performing identities and navigating belonging online. Journal of Youth Studies, 21(2), 129-143.

Goffman, E. (1959). The Presentation of Self In Everyday Life. Garden City, NY: Anchor.

Golden, D. (2015). Using the four layers of identity to become a leader. Retrieved on 14.10.2019: https://www.linkedin.com/pulse/using-four-layers-identity-becomeleader-douglas-golden

Hatzipanagos, S., \& Warburton, S. (2013). Digital Identity And Social Media.

IGI global. London.

Hecht, M. L. (1993). A research odyssey: Towards the Development of a Communication Theory Of Identity. Communication Monographs, 60, 76-82.

Hope, E. C., Gugwor, R., Riddick, K. N., \& Pender, K. N. (2019). Engaged against the machine: Institutional and cultural racial discrimination and racial identity as predictors of activism orientation among Black youth. American journal of community psychology, 63(1-2), 61-72.

Huang, J., Kumar, S., \& Hu, C. (2020). Does Culture Matter? A Comparative Study on the Motivations for Online Identity Reconstruction Between China and Malaysia. SAGE Open, 10(2), 2158244020929311.

ITU. (2017). 70\% of the World's Youth are Online. Retrieved on 12.03.2019. from https://milunesco.unaoc.org/mil-resources/70-of-the-worlds-youth-are-online/

Ivancic, L., Cairns, K., Shuttleworth, L., Welland, L., Fildes, J. \& Nicholas, M. (2018), Lifting The Weight: Understanding Young People's Mental Health And Service Needs In Regional And Remote Australia. Sydney: ReachOut Australia and Mission Australia

Jaynes, V. (2020). 'Befriend them but not be their friend': Negotiations of youth practice in a digital age. Journal of Youth Studies, 23(2), 205-220.

Jhangiani, R. \& H. Tarry. (2014). Principles of Social Psychology - 1st International Edition. Victoria, B.C.: BC campus. Retrieved from https://opentextbc.ca/socialpsychology

Jung, E., \& Hecht, M. L. (2004). Elaborating the Communication Theory Of Iden-Tity: Identity Gaps and Communication Outcomes. Communication Quarterly, 52, 265-283. 
International Journal of Business Management, Entrepreneurship and Innovation, Volume 3, Issue 2, 2021, PP 15-30, ISSN 2707-8027

BED

Kaakinen, M., Sirola, A., Savolainen, I., \& Oksanen, A. (2020). Shared identity and shared information in social media: development and validation of the identity bubble reinforcement scale. Media Psychology, 23(1), 25-51.

Kaigwa, M. (2013). How Social Media Has Increased The Pace Of Change. Retrieved 20.1.2019 from https://www.theguardian.com/global-development-professionalsnetwork/2013/dec/13/kenya-social-media-mark-kaigwa

Katz, E., Jay, Blumler, J.G \& Gurevitch, M (1974) "Uses and Gratifications Research."The Public Opinion Quarterly 4. 3738.

Kelly, K. (2006). Research in Practice: Applied Methods For The Social Sciences. University of Cape Town press.

Kenya Mobile Report (2019). Kenyan Facts: Kenya is Africa's Silicon Savannah. Retrieved on 05.04.2020 from: https://www.mobilereport.co.ke/sp

Kim, S., Kandampully, J., \& Bilgihan, A. (2018). The influence of eWOM communications: An application of online social network framework. Computers in Human Behavior, 80, 243-254.

Lawless, B. (2015). Performing Identity in "Transforming Poverty Partnerships": An Extension of Critical Discourse Analysis. Howard Journal Of Communications. 26 10.1080/10646175.2015.1049758

Ling, R., \& Pedersen, E. (2003). Modifying adoption research for mobile internet service adoption: Cross-disciplinary interactions. In: Proceeding of the 36th Hawaii International Conference on System Sciences. Hawaii: The Computer Society.

Literat, I. (2021). "Teachers Act Like We're Robots": TikTok as a Window Into Youth Experiences of Online Learning During COVID-19. AERA Open, 7, 2332858421995537.

Lumen, M. (2019). Symbolic Interactionist Theory. Retrieved on 08.02.2020 from https://courses.lumenlearning.com/alamo-sociology/chapter/reading-symbolicinteractionist-theory/

Matig, J, M. (2018). Message Effects And The Communication Theory Of Identity. Retrieved on 20.7.2019 from https://uknowledge.uky.edu/cgi/viewcontent.cgi?article=1066\&context=comm_etds

Mazur, E., \& Richards, L. (2011). Adolescents' and Youth' Social Networking Online: Homophily or diversity? Journal of Applied Developmental Psychology, 32(4), 180-188.

McQuail, D., \& Windahl, S. (1981). Communication models for the study of mass communications. London: Longman.

Meeus, W., Van de Schoot, R., Keijsers, L., Schwartz, S. J., \& Branje, S. (2010). On the progression and stability of adolescent identity formation. A five-wave longitudinal study in early-to-middle and middle-to-late adolescence. Child Development, 81, 1565-1581. doi: 10.1111/j.1467-8624.2010.01492

Miller, J. (2010). Language Use, Identity, and Social Interaction: Migrant Students in Australia.

Retrieved on

4.08.2017 https://www.tandfonline.com/doi/abs/10.1207/S15327973RLSI3301_3

Minister of Finance. (2012). Launch of the Youth Access To Government Procurement Opportunities (YAGPO) Program, 29th July 2012, KICC.

Ministry of Youth Affairs. (2020). The National Youth Policy. Nairobi: Government of Kenya Press

Morelli, A. (2018). Adolescents and Self-Identity. Retrieved on 16.07.2019 from https://www.risas.org/poc/view_doc.php?type=doc\&id=41163\&cn=1310

National Research Council. (1999). Funding a Revolution: Government Support for 
International Journal of Business Management, Entrepreneurship and Innovation, Volume 3, Issue 2, 2021, PP 15-30, ISSN 2707-8027

BED

Computing Research. Washington, DC: The National Academies Press. Retrieved on 12.11.2019 from https://doi.org/10.17226/6323.

National Youth Population. (2020). The National Youth Policy. Nairobi: Government of Kenya Press

Nguyen, M. H. (2017). Social Media And Youth Risk Behaviours: A mini-review.

Proceedings of International Conference, The First Southeast Asia Regional Conference of Psychology "Human Well-Being and Sustainable Development". 2, pp. 292-302. Ha Noi: Vietnam National University Press. 2.

Nikou, S., Cavalheiro, S., \& Widén, G. (2020, March). Digital natives and digital immigrants in the creative economy. In International Conference on Information (pp. 343-362). Springer, Cham.

Pegg, K. J., O'Donnell, A. W., Lala, G., \& Barber, B. L. (2018). The role of online social identity in the relationship between alcohol-related content on social networking sites and adolescent alcohol use. Cyberpsychology, Behavior, and Social Networking, 21(1), $50-55$.

Perks, L. G., \& Turner, J. S. (2019). Podcasts and productivity: A qualitative uses and gratifications study. Mass Communication and Society, 22(1), 96-116.

Pew Research Center. (2019). Demographics of Internet Users. Pew Internet and American Life Project. Retrieved on 11.1.2020 from http://www.pewinternet.org/TrendData/Whos-Online.aspx.

Reis, L., Mercer, K., \& Boger, J. (2021). Technologies for fostering intergenerational connectivity and relationships: Scoping review and emergent concepts. Technology in Society, 64, 101494.

Reimenschneider, C.K., Buche, M.W. \& Armstrong, D.J. (2019). He Said, She Said:

Communication Theory of Identity and the Challenges Men Face in the Information Systems Workplace. Retrieved on 27.02.2020 from https://dl.acm.org/doi/abs/10.1145/3353401.3353407?download=true

Roth-Ebner, C. (2019). Digital Culture, New Media And Youth. Retrieved from: https://www.ecrea.eu/page-18206/7854713

Roux, T. (2020). Users' Experience of Digital Wayfinding Screens: A Uses and Gratification Perspective from South Africa. Advances in Human-Computer Interaction, 2020.

Savolainen, I., Oksanen, A., Kaakinen, M., Sirola, A., Zych, I., \& Paek, H. J. (2021). The role of online group norms and social identity in youth problem gambling. Computers in Human Behavior, 106828.

Sikolia, G. S. (2015). Factors influencing the choice of social network sites among high school teenagers in Nairobi, Kenya. Unpublished doctoral thesis, Jomo Kenyatta University of Agriculture and Technology, Juja, Kenya.

SimeLab (2018). Kenya social media landscape: Trends and emerging narratives. Retrieved on08.02.2020from:https://www.usiu.ac.ke/assets/image/Kenya_Social_Media_Lansca pe_Report_2020.pdf

Sulimani-Aidan, Y., Melkman, E., \& Hellman, C. M. (2019). Nurturing the hope of youth in care: The contribution of mentoring. American Journal of Orthopsychiatry, 89(2), 134.

The Constitution of Kenya. (2010). Retrieved on 15.04.2020. From: https://www.refworld.org/docid/4c8508822.html

UN Chronicles. (2017). Youth Lead The Way To A More Connected And Sustainable World. Retrieved on 4.03.2019 from https://unchronicle.un.org/article/youth-lead-way-moreconnected-and-sustainable-world

UNFPA. (2020). State of World population 2019: People and possibilities in a world of 7 billion. New York: UNFPA. 
International Journal of Business Management, Entrepreneurship and Innovation, Volume 3, Issue 2, 2021, PP 15-30, ISSN 2707-8027

UNICEF. (2017). Children in a Digital World. Retrieved on 22.04 .2019 from: https://www.unicef.org/publications/files/SOWC_2017_ENG_WEB.pdf

US Department of Education. (2017). Reimagining the Role of Technology in Education.

Retrieved on 11.11.2019 from: https://tech.ed.gov/files/2017/01/NETP17.pdf

Waithaka, M. W. (2013). Internet Use among University Students. A Case Study of the University of Nairobi. A Master Thesis. erepository.uonbi.ac.ke:8080/.../thesisRetrieved on 8/1/2017

Waithaka, M, Onyancha, O \& Ngulube, P. (2018). Internet Use Among University Students In Kenya: a case study of the University of Nairobi. VL - 57

Yin, R.K. (1989). Case Study: Research Design and Methods. 2nd ed. London. Sage Publications

Zupanick, C.E. (2015). Erik Erikson and Self-identity. Retrieved on 18.05.2018 from:

https://www.risas.org/poc/view_doc.php?type=doc\&id=41163\&cn=1310

This is an open-access article published and distributed under the terms and conditions of the (c) (i) (8) States unless otherwise stated. Access, citation and distribution of this article is allowed with full recognition of the authors and the source. 